\title{
Revisiting the role of within-compound associations in cue-interaction phenomena
}

\author{
David Luque • Amanda Flores • \\ Miguel A. Vadillo
}

Published online: 1 July 2012

(C) Psychonomic Society, Inc. 2012

\begin{abstract}
Although it is thought that within-compound associations are necessary for the occurrence of both backward blocking and unovershadowing, it is not known whether this variable plays a similar role in mediating the two phenomena. Similarly, the roles of within-compound associations in forward blocking and in reduced overshadowing have not been tested independently. The present experiments evaluated how the strength of withincompound associations affects backward blocking, unovershadowing, forward blocking, and reduced overshadowing. Using an allergy task, the strength of within-compound associations was varied by taking advantage of the participants' prior knowledge of common and uncommon food pairings. Backward blocking and unovershadowing effects were present only when highly memorable compound cues were used. Moreover, the magnitudes of both retrospective revaluation effects were affected by the strength of withincompound associations. Forward blocking and reduced overshadowing effects were independent of within-
\end{abstract}

\author{
D. Luque $\cdot$ A. Flores \\ University of Málaga, \\ Málaga, Spain \\ M. A. Vadillo \\ University of Deusto, \\ Bilbao, Spain \\ M. A. Vadillo \\ University College London, \\ London, UK \\ D. Luque $(\bowtie)$ \\ Departamento de Psicología Básica, Facultad de Psicología, \\ Universidad de Málaga, \\ Campus de Teatinos, $\mathrm{s} / \mathrm{n}$, \\ 29072 Málaga, Spain \\ e-mail: david.luque@gmail.com
}

compound associations. These results have important theoretical implications for causal learning research.

Keywords Backward blocking $\cdot$ Blocking $\cdot$ Causal learning $\cdot$ Reduced overshadowing $\cdot$ Unovershadowing

Learning causal relations from the environment allows us to both predict and control events that are relevant for survival. It is not surprising, therefore, that the specific mechanisms that underlie causal learning have been a subject of active research during the last few decades. A family of empirical phenomena, usually described as cue-interaction effects, has played a crucial role in the experimental study of causal learning (De Houwer, 2009; Gopnik et al., 2004; Holyoak \& Cheng, 2011; López \& Shanks, 2008; Mitchell, De Houwer, \& Lovibond, 2009; Shanks, 2007, 2010). According to the main results of the relevant literature, the successful learning of cue-outcome relationships depends on both the contingency (or statistical relationship) between a particular cue and an associated outcome and the existence of alternative predictors of the outcome in question.

Imagine, for instance, that after an experience with eating yogurt, the taste of yogurt becomes a good predictor of developing a stomachache. If this highly predictive cue is then presented along with a new food (e.g., honey) on some other occasion, and if the combination of foods also predicts the onset of a stomachache, it is unlikely that the added food will be considered a true cause of stomachache. This is an illustration of the so-called blocking effect, which was initially demonstrated in the area of animal conditioning (Kamin, 1968) and which is an effect that has played a major role in the development of human contingency learning theories (Dickinson, Shanks, \& Evenden, 1984). In a typical blocking experiment, participants are first exposed to a series of pairings of a cue, A, and an outcome, O (i.e., $\mathrm{A} \rightarrow \mathrm{O}$ ). In a subsequent experimental phase, the participants 
are exposed to trials on which a novel cue, $\mathrm{B}$, is presented in conjunction with cue $\mathrm{A}$, and the compound containing cues $\mathrm{A}$ and $\mathrm{B}$ is then a predictor of the outcome (i.e., $\mathrm{AB} \rightarrow \mathrm{O}$ ). The usual result is that participants fail either to learn the $\mathrm{B} \rightarrow \mathrm{O}$ association or to express knowledge of this association if it has been learned. In other words, learning the $\mathrm{A} \rightarrow \mathrm{O}$ association impairs, or blocks, the learning of the $\mathrm{B} \rightarrow \mathrm{O}$ association.

Standard associative learning theories can easily account for this blocking effect. For instance, in the previous example, the well-known learning algorithm that was proposed by Rescorla and Wagner (1972) predicts that the association between honey and the outcome (stomachache) will not be strengthened during the compound trials, because yogurt alone already perfectly predicts the presence of the outcome. Thus, honey would be a redundant cue; the presence or absence of honey offers no additional information about the subsequent occurrence of the illness (Rescorla \& Wagner, 1972; see also, e.g., Sutton \& Barto, 1981).

Some of the classical theories of learning, including the Rescorla-Wagner model cited above, fail to account for another group of cue-interaction phenomena, which are known as retrospective revaluation effects. These effects are characterized by the modification of a previously learned cue-outcome link that results from the subsequent development of an association between another cue and the same outcome (or between another cue and the absence of the outcome). For instance, in a backward blocking design, a compound that contains two separate cues, A and B, is paired with an outcome. Later, one of the elements of the compound, A, is paired repeatedly with the same outcome (i.e., a series of $A B \rightarrow O$ trials is followed by a series of $\mathrm{A} \rightarrow \mathrm{O}$ trials; see Table 1). If the association between the other element of the compound, $\mathrm{B}$, and the outcome, $\mathrm{O}$, is subsequently tested, participants who have been exposed to $\mathrm{A} \rightarrow \mathrm{O}$ pairings generally have a lower subjective estimation of the causal strength between $\mathrm{B}$ and $\mathrm{O}$ than do control participants who were not exposed to $\mathrm{A} \rightarrow \mathrm{O}$ pairings.

The experimental design in studies of the unovershadowing effect is very similar to the design used in studies investigating backward blocking; the only difference between the two experimental setups is that the cue presented in isolation is associated with the absence of the outcome $\mathrm{O}$ (i.e., a series of $\mathrm{EF} \rightarrow \mathrm{O}$ trials is followed by a series of $\mathrm{E} \rightarrow$ noO trials; see Table 1). In a posttraining test of the causal strength of cue $\mathrm{F}$, the typical result is a higher subjective estimation of the strength of the causal relation between $\mathrm{F}$ and $\mathrm{O}$ among participants who were exposed to $\mathrm{E} \rightarrow$ noO trials than among participants in the control condition (e.g., Wasserman \& Berglan, 1998).

According to classical associative models, modifications of a cue-outcome association can occur only during trials on which this cue is present. Thus, classical models of associative learning predict that no learning about cue $\mathrm{B}$ or cue $\mathrm{F}$ will occur during the second phases of backward blocking or unovershadowing experiments, respectively (Shanks, 1985). In other words, these models cannot account for the retrospective actualizations of the cue-outcome links that characterize retrospective revaluation phenomena. However, it is relatively easy to adapt or extend classical models so that they can successfully account for retrospective learning about missing cues (Dickinson \& Burke, 1996; Markman, 1989; Tassoni, 1995; Van Hamme \& Wasserman, 1994).

Some of the revised models that have been proposed assume that a within-compound association between the cues in a given compound develops because the cues are paired with each other and with the outcome during the first training stage of a retrospective revaluation experiment. This within-compound association will then mediate any subsequent cue-interaction processes that may take place. For instance, the models proposed by Dickinson and Burke

Table 1 Summary of experimental designs

\begin{tabular}{|c|c|c|c|c|c|}
\hline & Group & Condition & Phase 1 & Phase 2 & Test \\
\hline \multirow[t]{6}{*}{ Experiment 1} & \multirow{3}{*}{$\begin{array}{l}\text { UsC [common pairs of foods: } \\
\text { e.g., macaroni and cheese] }\end{array}$} & Backward blocking & $\mathrm{AB} \rightarrow \mathrm{O}$ & $\mathrm{A} \rightarrow \mathrm{O}$ & $\mathrm{B}$ ? \\
\hline & & Control (overshadowing) & $\mathrm{CD} \rightarrow \mathrm{O}$ & - & C? D? \\
\hline & & Unovershadowing & $\mathrm{EF} \rightarrow \mathrm{O}$ & $\mathrm{E} \rightarrow \mathrm{noO}$ & $\mathrm{F} ?$ \\
\hline & \multirow{3}{*}{$\begin{array}{l}\text { UnC [uncommon pairs of } \\
\text { foods: e.g., grapes and } \\
\text { noodles] }\end{array}$} & Backward blocking & $\mathrm{AB} \rightarrow \mathrm{O}$ & $\mathrm{A} \rightarrow \mathrm{O}$ & $\mathrm{B} ?$ \\
\hline & & Control (overshadowing) & $\mathrm{CD} \rightarrow \mathrm{O}$ & - & C? D? \\
\hline & & Unovershadowing & $\mathrm{EF} \rightarrow \mathrm{O}$ & $\mathrm{E} \rightarrow \mathrm{noO}$ & $\mathrm{F} ?$ \\
\hline \multirow[t]{6}{*}{ Experiment 2} & \multirow{3}{*}{$\begin{array}{l}\text { UsC [common pairs of foods: } \\
\text { e.g., macaroni and cheese] }\end{array}$} & Forward blocking & $\mathrm{A} \rightarrow \mathrm{O}$ & $\mathrm{AB} \rightarrow \mathrm{O}$ & $\mathrm{B}$ ? \\
\hline & & Control (overshadowing) & - & $\mathrm{CD} \rightarrow \mathrm{O}$ & C? D? \\
\hline & & Reduced overshadowing & $\mathrm{E} \rightarrow \mathrm{noO}$ & $\mathrm{EF} \rightarrow \mathrm{O}$ & $\mathrm{F} ?$ \\
\hline & \multirow{3}{*}{$\begin{array}{l}\text { UnC [uncommon pairs of } \\
\text { foods: e.g., grapes and } \\
\text { noodles] }\end{array}$} & Forward blocking & $\mathrm{A} \rightarrow \mathrm{O}$ & $\mathrm{AB} \rightarrow \mathrm{O}$ & $\mathrm{B}$ ? \\
\hline & & Control (overshadowing) & - & $\mathrm{CD} \rightarrow \mathrm{O}$ & $\mathrm{C}$ ? D? \\
\hline & & Reduced overshadowing & $\mathrm{E} \rightarrow \mathrm{noO}$ & $\mathrm{EF} \rightarrow \mathrm{O}$ & $\mathrm{F} ?$ \\
\hline
\end{tabular}


(1996) and Van Hamme and Wasserman (1994) assume that the associative strengths of both cues that are present and cues that are absent (but that are expected) can and do change. The mechanism by which absent cues can be expected is the presence of a within-compound association between the absent cue and other cues that happen to be present. Therefore, the representation of cue B (or F) is somehow active during the second phase of the experiment, which allows participants to learn about the cue.

In a different vein, the comparator hypothesis (Miller \& Matzel, 1988; Stout \& Miller, 2007) proposes that the activation of the representation of $\mathrm{O}$ in a test will depend on a comparison of the relative associative strengths of the cues that appear within a compound stimulus in the first phase of an experiment. The comparator hypothesis also notes that this comparison is triggered by a within-compound association. Backward blocking would then take place because the second learning phase results in the development of an association between cue $\mathrm{A}$ and outcome $\mathrm{O}$ that is stronger in the experimental condition than in the control condition. Therefore, the association between B and the outcome is poorly expressed, relative to the control condition. Similarly, unovershadowing occurs because the $\mathrm{E} \rightarrow \mathrm{O}$ association is weakened during the second phase of the experiment; thus, when the $\mathrm{E} \rightarrow \mathrm{O}$ and $\mathrm{F} \rightarrow \mathrm{O}$ associations are compared in a posttest, the $\mathrm{F} \rightarrow \mathrm{O}$ association is expressed without opposition. Thus, the models of causal learning that are most relevant for our study, including the comparator hypothesis, make a fundamental assumption that retrospective revaluation depends on the formation of a withincompound association between two cues that are presented in the same compound during the first learning phase (see Ghirlanda, 2005, and Kruschke \& Blair, 2000, for alternate accounts of causal learning that are independent of withincompound associations).

The aim of Experiment 1 was to examine whether withincompound associations are independently related to backward blocking and unovershadowing effects. According to the aforementioned models, both of these effects should be affected by the degree to which cue A is associated with cue $\mathrm{B}$ during the first learning phase. Although many studies have shown that within-compound associations are involved in retrospective revaluation effects in general (Aitken, Larkin, \& Dickinson, 2001; Dickinson \& Burke, 1996; Larkin, Aitken, \& Dickinson, 1998; Melchers, Lachnit, \& Shanks, 2004, 2006; Mitchell, Killedar, \& Lovibond, 2005; Vandorpe, De Houwer, \& Beckers, 2007), it is difficult to determine the independent effects of these associations on backward blocking and unovershadowing in many of these studies, because the unovershadowing and backward blocking conditions have often been used as controls for each other. A condition that could be used as a control for both effects, such as an overshadowing condition (as proposed by
Wasserman \& Berglan, 1998, and Shanks, 1985; the same control was also proposed by Dickinson \& Burke, 1996, footnote 3 ), is excluded from most of these experiments, so it is impossible to separately draw firm conclusions about backward blocking and unovershadowing.

For instance, Dickinson and Burke (1996) manipulated the strengths of the within-compound associations in an experiment that used both backward blocking and unovershadowing. In their consistent condition, cue A appeared in conjunction with cue B during the first learning phase, which allowed for the normal formation of an association between the two cues. However, in their varied condition, cue B was associated with cue A on some trials and with other distracting cues on others. It was then expected that the association between cues A and B would be weaker in the varied condition than in the consistent condition, but the strengths of the within-compound associations in the two conditions were not measured. The experimental design of this experiment included both backward blocking and unovershadowing conditions, but it did not include any other control condition(s). When the participants were subsequently asked to assess the causal strength of cue B in a posttest, their ratings were lower in the backward blocking condition than in the unovershadowing condition, but this observation was true only for participants who had been exposed to the condition in which the cues were consistently paired.

Although Dickinson and Burke's (1996) result showed that it is possible to learn about cues that are absent during the second learning phase and that within-compound associations are likely to be involved in the process, it is not possible to determine whether the observed effect influenced backward blocking, unovershadowing, or both effects. Unfortunately, other studies that have been conducted to assess the role of within-compound associations in retrospective revaluation have similar methodological problems (Aitken et al., 2001; Dickinson \& Burke, 1996; Melchers et al., 2004, 2006; Mitchell, Killedar, \& Lovibond, 2005; Vandorpe et al., 2007).

Interestingly, it appears that backward blocking and unovershadowing could result from different processes to some extent. This hypothesis is supported by previous research that shows that unovershadowing effects are easier to obtain and/or stronger than backward blocking effects. For instance, a significant unovershadowing effect was observed in an experiment by Wasserman and Berglan (1998), whereas the backward blocking effect in their experiment did not become significant until they removed participants with lower levels of within-compound associations from the analysis (see also Larkin et al., 1998). Unfortunately, it is difficult to appropriately assess the hypothesis that unovershadowing and backward blocking are mediated by different processes, because most retrospective revaluation experiments lack an overshadowing control condition. 
We find a similar confound in the published studies of forward cue interaction. Forward cue-interaction effects are parallel to retrospective revaluation effects, but they occur when the learning phases are reversed (Table 1). Many previous studies of forward blocking and reduced overshadowing also suffer from the lack of an independent overshadowing control condition (e.g., Melchers et al., 2004, 2006). In Experiment 2, we tested the extent to which within-compound associations affect forward blocking and reduce overshadowing. Although the comparator theory predicts that both forward blocking and reduced overshadowing effects will necessarily be similarly affected by the strength of within-compound associations, other models, such as one that was proposed by Van Hamme and Wasserman (1994), predict that these forward cueinteraction effects will remain relatively unaffected by within-compound associations.

\section{Experiment 1}

The main goal of Experiment 1 was to determine whether the backward blocking and unovershadowing effects in causal learning are similarly affected by changes in the strengths of within-compound associations. To achieve this goal, we manipulated ${ }^{1}$ the strengths of the within-compound associations in stimuli that were used in a standard allergy task (Wasserman, 1990). The design of our experiment included a within-subjects retrospective revaluation manipulation that was similar to the one used in a study conducted by Wasserman and Berglan (1998). Thus, our design included a backward blocking condition, an unovershadowing condition, and importantly, an overshadowing control condition that could be used to assess the magnitudes of the backward blocking and unovershadowing effects independently. To change the strengths of the within-compound associations, we used a two-level, between-subjects manipulation. In the unusual-compounds $(\mathrm{UnC})$ group, the stimuli that were used as cues were the same as those used by Wasserman and Berglan. In general, these foods are rarely eaten together. Alternatively, in the usual-compounds (UsC) group, the stimuli utilized as cues were pairs of food that are frequently eaten together (e.g., strawberries and cream) (Mitchell, Lovibond, \& Gan, 2005).

\footnotetext{
${ }^{1}$ Although we have used the term manipulate in this context, we did not manipulate this variable in a narrow sense, because the larger within-compound associations between the food pairs that were used in the UsC condition were not developed via laboratory training. Despite this, however, we think that the results of the withincompound association tests help to mitigate concerns about possible confounding extraexperimental differences in the participants' judgments of the stimuli.
}

In addition, two complementary tests were used to measure the strengths of the within-compound associations at the end of the experiment. The first of these tests was the recognition test used by Wasserman and Berglan (1998; see also Aitken et al., 2001; Melchers et al., 2004, 2006; Wasserman \& Castro, 2005). In this test, the participants were asked to identify pairs of cues that they had seen during the first learning phase among other distractor cue compounds. Because there were only four compounds that could be correctly recalled, the recognition test scores ranged from 0 to 4 .

After the recognition test, the participants were asked to participate in an additional test that was aimed at increasing the variability of the measure of the strength of the withincompound associations (see Larkin et al., 1998, for a related memory test). In the second test, participants were asked to rate the extent to which they were confident in their previous selections in the recognition test. Thus, each participant provided two related measures of his or her ability to remember the compounds that had been used in the experiment—namely, the number of correctly identified compounds and the level of confidence that each participant had in his or her selections. An additional goal of this experiment was to determine whether this double test of the strength of within-compound associations offers any advantage over the classic recognition test.

\section{Method}

\section{Participants and apparatus}

In total, 92 students at the University of Málaga School of Psychology received course credit for voluntary participation in this study. The students were randomly assigned to the two experimental condition groups; 52 students were included in the UnC condition group, and 40 students were included in the UsC condition group.

Each participant performed the task on 1 of 10 PCs in a semi-isolated cubicle. Each PC had been equipped with custom-built software that was programmed in Visual Basic 2005 (Microsoft, USA). Participants indicated their responses using the keyboard and the mouse of the PC.

\section{Stimuli and procedure}

Stimuli Eight different food names were taken from Wasserman and Berglan's (1998) study and were used as cues in the UnC condition. These food names were walnuts, mushrooms, grapes, yoghurt, noodles, oranges, chicken, and carrots. Cue pairings in the UnC condition were counterbalanced. A different set of eight food names (making up four pairs) that had been adapted from Mitchell, Lovibond, \& Gan, (2005) was used in the UsC condition and included 
the following pairs: macaroni and cheese, strawberries and cream, tea and coffee, and bread and butter. The assignment of the various food names to individual cues in the UsC condition was only partially counterbalanced so that the food pairings that commonly co-occur in extraexperimental contexts also appeared together as compound cues during the experiment. The cues were written in black type and appeared at the center of the screen. For trials on which two cues were presented, the position of each cue on the screen (right or left) was randomized across trials. The phrases "Allergy" or "No Allergy" were used as outcomes (O and noO, respectively; see Table 1) and appeared as text that was positioned below the cues in the center of the screen. Participants were given feedback about their choices on each trial via messages stating either "Incorrect!" (written in red) or "Correct!" (written in green).

Procedure With the exception of the additional memory test that was used after the traditional recognition test, all of the details of our procedure, instructions, and questionnaires were kept similar to those used in Wasserman and Berglan's (1998) study. The participants began the experiment by reading the instructions on the computer screen. In the instructions, they were asked to imagine that they were allergists who were attempting to determine which foods were causing a fictitious patient, Mr. X, to experience an allergic reaction. To do so, the participants were required to study the results of a series of daily allergy tests in which Mr. X did or did not suffer from an allergic reaction after eating certain foods.

After they had finished reading all of the instructions and their questions had been answered, the participants were asked to rate the likelihood that each of the foods that would eventually be used as a cue could cause an allergic reaction in an ordinary person. Participants were instructed to answer on a scale ranging from 0 to 9 , in which a score of 0 indicated that it [the food] does not cause any allergic reaction at all and a score of 9 indicated that it [the food] causes a strong allergic reaction.

After obtaining these preliminary data, the participants began performing the actual causal learning task. Each learning trial represented an allergy test performed on $\mathrm{Mr}$. $\mathrm{X}$. These trials began with the presentation of the foods that had been eaten by Mr. X (i.e., the cues) in that particular allergy test at the center of the top of the screen. After $3 \mathrm{~s}$, the participants were asked to decide whether Mr. X would suffer an allergic reaction and to indicate their decisions by pressing one of two keys: the "A" key was used to indicate that they expected Mr. $\mathrm{X}$ to have an allergic reaction, and the " $\mathrm{N}$ " key was used to indicate that they did not expect him to have an allergic reaction. After a participant had pressed the key that indicated his or her choice, the outcome and the feedback appeared on the screen, thereby allowing the participants to learn the correct cue-outcome associations.

During the first learning phase of the experiment, the participants had to learn to identify four food pairings that could potentially cause an allergic reaction in $\mathrm{Mr}$. X. In this phase, compounds $\mathrm{AB}, \mathrm{CD}$, and $\mathrm{EF}$ were always paired with an allergic reaction, and the filler compound GH was always paired with the absence of a reaction. Each compound was presented 30 times in a pseudorandomized presentation order, with the constraint that each compound was presented 6 times during each 24-trial series. After the first learning phase, participants were instructed to respond to the same questionnaire that had been presented at the beginning of the experiment; however, they were instructed to answer the questions on the questionnaire using the information that they had learned about Mr. X during the first learning phase. The participants were not given access to the ratings that they had provided in previous questionnaires.

After completing the second questionnaire, each participant began the trials that made up the second learning phase. In this phase, cue A was always paired with the allergic reaction, and cues $E$ and $G$ were always paired with the absence of an allergic reaction. Each cue was presented 30 times according to a pseudorandom order of presentation; the constraint for ordering during this phase was that each cue had to be presented 6 times in every block of 18 trials. After the second learning phase, participants were again instructed to respond to the questionnaire regarding the causal efficacy of each food in producing an allergic reaction. In this case, the participants were asked to consider all of the information that they had learned throughout both phases of the experiment. The ratings that the participants provided while responding to this questionnaire (specifically, the ratings for cues $\mathrm{B}, \mathrm{C}, \mathrm{D}$, and F) were used as dependent variables in the subsequent measurement of cue-interaction phenomena.

After completing the third questionnaire, each participant performed two memory tests that were aimed at measuring his or her ability to remember the compounds that had been established during the first training phase. The first of these tests was the recognition test used by Wasserman and Berglan (1998). In this test, the participants had to select the four compounds that had actually been presented during the task among 16 pairs of food. The 12 incorrect food pairs were new compounds that were formed by pairing the eight foods that had been tested in a different way. The second memory test requested that the participants assess their levels of confidence in each of the selections that they had made in the recognition test. Participants were asked to rate their confidence levels on a scale of 0 to 9 , in which a score of 0 indicated being completely unconfident and a score of 9 indicated being absolutely confident. 


\section{Data analysis}

In contrast to previous studies of cue interaction, we used a nonparametric approach to the analysis of our data. This decision deserves some comment. The nonparametric approach is highly recommended for analyzing the current data because the dependent variables are ordinal in nature (single Likert-type items). The main dependent variables that were used in our experiment were ratings associated with the probability that each food would cause the fictitious patient, Mr. X, to have an allergic reaction. Participants were asked to make these ratings by choosing among a set of ordered categories (from 0 to 9). We can determine whether a participant rates one causal relation as being stronger than a different causal relation, but we cannot determine the magnitude of the distance between these ratings, because we do not have a measure of the relation between our measurement tool and the causal belief of the participants (the underlying factor in generating ratings). For instance, it is possible that the difference between 0 and 1 reflects a greater difference in the underlying factor than does the difference between 1 and 2. However, according to the Likert-type item score, the distance between each pair of values - namely, one point-is the same.

Although the recognition test (which measured the number of compounds that were correctly remembered) was not a Likert-type item, this variable was also an ordinal variable, because the correct recognition of a higher number of compounds indicates the presence of stronger within-compound associations. Again, we cannot determine the magnitudes of the distances between the different levels of the underlying factor (the memory for compounds) that produce variations in the measured variable.

The critical reader might argue that because parametric analyses facilitate the analysis of complex interactions, it is preferable to assume that there are some minor inaccuracies in the statistical analyses and to conduct the parametric tests, even when an experiment uses ordinal dependent variables. It is important to note that several articles that discourage the use of parametric analyses for ordinal dependent variables have been published in other fields. For example, treatment efficacy in psychiatric research is frequently measured via rating scales that are very similar to the scales that are used to measure the dependent variables in causal learning experiments. Munzel and Bandelow (1998) strongly criticized the generalized use of parametric analyses in the studies that used ratings to measure treatment efficacy. In the field of plant pathology, the severity of plant diseases is often assessed according to an ordinal rating scale, rather than a continuous scale. Shah and Madden (2004) criticized the use of parametric analyses in these studies, and they proposed the use of nonparametric alternatives. In the field of epidemiology, Kahler, Rogausch, Brunner, and Himmel
(2008) observed that even though many measures of healthrelated quality of life aspects are ordinal, the data are typically analyzed using parametric tests. These authors examined whether applying parametric tests (instead of the appropriate nonparametric tests) to these quality of life data could affect the results and found that using parametric tests to analyze ordinal data could lead to erroneous results (see also Norris, Ghali, Saunders, Brant, \& Galbraith, 2004; Singer, Poleto, \& Rosa, 2004).

The ordinal nature of our dependent variables was not the only reason that parametric analyses of our data were not feasible; most of the dependent variables were also nonnormally distributed. For example, the judgments about both cue $\mathrm{B}$ and cue $\mathrm{F}$ in the final questionnaire were not normally distributed. We attempted to improve the normality of our data by performing some common data transformations, including $\log (\mathrm{X}+1)$, $\operatorname{sqrt}(\mathrm{X})$, and $1 /(\mathrm{X}+1)$. However, Kolmogorov-Smirnov tests showed that the distributions that resulted from all of these transformations were still significantly different from the normal distribution.

In summary, the reasons to avoid applying parametric analyses to our data have been described many times (for a classical reference, see Siegel \& Castellan, 1988, Chapter $3)$. The statistical models that underlie parametric analyses assume that the dependent variables are continuous and normally distributed. Applying this type of model to a dependent variable that is ordinal and nonnormal may produce deviations in the obtained $p$ value. Even if the deviation in the $p$ value is not dramatic, the impact of it is difficult to quantify. Thus, a nonparametric analysis is strongly recommended, because it is more conservative than the parametric alternative and because a nonparametric analysis maximizes statistical power.

Even so, because we are aware that very different statistical tests have been used to analyze these types of variables in the past, and to avoid any suspicion regarding an attempt to avoid ambiguous results from other types of statistical tests, we have also repeated all of our analyses using equivalent parametric tests. These complementary parametric analyses were performed in the same manner as in previous experiments; that is, parametric analyses of variance (ANOVAs) were used in conjunction with additional $t$-tests when necessary (e.g., Melchers et al., 2004). Any differences between the results of the parametric and nonparametric analyses that we observed are reported below.

An important limitation of the use of ordinal variables is that they can neither be summed nor subtracted. This limitation implies, for instance, that we cannot average the mean responses to cues $\mathrm{C}$ and $\mathrm{D}$ to compute an "overshadowing" control variable, although this is commonly done in the general research area of the present study (e.g., Melchers et al., 2006). Therefore, we conducted all of the analyses 
that involved the overshadowing control condition twice; the first analysis used cue $\mathrm{C}$ to represent the control condition, and the second used cue D. For the sake of simplicity, we have reported only the results of analyses in which cue $\mathrm{C}$ represented the control condition for cases in which both analyses yielded the same results.

In addition, because nonparametric analyses cannot be used to examine complex interactions, we needed to compute new variables that represented the strengths of the backward blocking and/or the unovershadowing effects for some analyses (Melchers et al., 2006). The magnitude of the backward blocking magnitude variable (mBB) was developed to sort the participants according to the degree to which they experienced backward blocking (the resultant variable was also ordinal). Thus, participants with lower ratings for cue $\mathrm{B}$ than for cues $\mathrm{C}$ and $\mathrm{D}$ were categorized as being participants who experienced higher levels of backward blocking (labeled as +2 ). For instance, a participant who provided a rating of 3 for cue $\mathrm{B}$ and ratings of 4 and 9 for cues $\mathrm{C}$ and $\mathrm{D}$, respectively, would have a $\mathrm{mBB}$ value of +2 . The next category, labeled as +1 , included participants who had lower ratings for B than for C or D. Participants were labeled as +1 if the ratings that they provided for one of the control cues (cue $\mathrm{C}$ or cue $\mathrm{D}$ ) were higher than the ratings that they provided for cue $\mathrm{B}$ and if the ratings for the other control cue were equal to their ratings for cue B. For example, a participant who provided a rating of 3 for cues $\mathrm{B}$ and $\mathrm{C}$ and a rating of 9 for cue $\mathrm{D}$ would have a $\mathrm{mBB}$ value of +1 . The next $\mathrm{mBB}$ category was 0 . This category included all of the participants who had provided equal ratings for cues $\mathrm{B}, \mathrm{C}$, and $\mathrm{D}$. It also included participants who gave a rating to one of the control cues that was higher than the rating that they had given to cue B but who gave a lower rating to the other control cue. For instance, a participant who had given ratings of 3, 2, and 9 to cues $\mathrm{B}, \mathrm{C}$, and $\mathrm{D}$, respectively, would have been assigned an $\mathrm{mBB}$ value of 0 . The $\mathrm{mBB}$ category below 0 was -1 , which included participants who had given one control cue a rating that was lower than the rating that they had given to cue $\mathrm{B}$ and who had given the other control cue a rating that was equal to the rating that they had attributed to cue B. For instance, a participant who had rated cues $\mathrm{B}, \mathrm{C}$, and $\mathrm{D}$ with scores of 3, 3, and 2 , respectively, would have an $\mathrm{mBB}$ value of -1 . The lower extreme of this ordinal variable was the -2 category. The $-2 \mathrm{mBB}$ category included participants who had given lower ratings to both of the control cues (C and $\mathrm{D})$ than they had given to cue $\mathrm{B}$.

The ordinal variable that was used to measure the magnitude of unovershadowing (mUN) was computed according to the same rules, but it was used as an index of the unovershadowing effect instead of the backward blocking effects (i.e., instead of ratings for cue B, ratings for cue $\mathrm{F}$ relative to ratings for the control cues were used in the computation of the mUN value for each participant).

To differentiate between participants who had either strong or weak within-compound associations, we used both the number of correctly remembered compounds from the recognition test (an ordinal variable that was ordered from 0 to 4) and the subsequent ratings that the participants provided during the confidence tests. The first recognition test allowed us to divide the sample into two groups. One group comprised the participants who had correctly identified all four compounds (the good recognition, [Good-Rec] group), and the other group comprised the remaining participants (the poor recognition [Poor-Rec] group; see Wasserman \& Berglan, 1998). A similar criterion was used to group the participants on the basis of their performance on the second (confidence) test. Participants who had correctly identified all four compounds and who had confidence ratings of 9 for their selections were included in the good recognition and confidence group (Good-Rec\&Con), whereas the remaining participants were included in the poor recognition and confidence group (Poor-Rec\&Con). The effects of both memory tests on backward blocking and unovershadowing were evaluated independently. Pairwise comparisons were used to control for type I errors at the .05 significance level.

\section{Results and discussion}

The medians of the causal ratings for each of the cues with their respective outcomes in each of the three rating periods are provided in Table 2 . These results indicate that the participants generally had low causal ratings at the beginning of the experiment. After the first phase of learning, the participants adjusted their ratings to be consistent with the programmed contingencies. Both the backward blocking and unovershadowing effects were evaluated using the ratings that were provided in the third questionnaire as dependent variables; these data were supplied after the completion of the second learning phase.

A Friedman test was conducted with the whole sample of participants, regardless of group, to evaluate the difference in the median ratings for cues B (median $=4), \mathrm{C}($ median $=$ 5 ), and $\mathrm{F}$ (median $=6$ ), and the observed difference was significant, $\chi^{2}(2, N=92)=15.07, p<.001$. Follow-up comparisons were conducted using a Wilcoxon test, which revealed that the median of the ratings for cue $\mathrm{F}$ was significantly higher than the medians of the ratings for both cue $\mathrm{C}$ $(p<.01)$ and cue B $(p<.001)$. Moreover, the median of the ratings for cue $\mathrm{C}$ was significantly higher than that of the ratings for cue $\mathrm{B}(p<.01)$. Thus, we can confirm that we obtained reliable backward blocking and unovershadowing effects. In addition, we also compared the strengths of the backward blocking and unovershadowing effects by making 
Table 2 Median ratings of all cues in Experiments 1 and 2 according to experimental conditions UnC and UsC

\begin{tabular}{|c|c|c|c|c|c|c|c|}
\hline \multirow[b]{2}{*}{ Condition } & \multirow[b]{2}{*}{ Cue } & \multicolumn{3}{|c|}{ Experiment 1 (Medians) } & \multicolumn{3}{|c|}{ Experiment 2 (Medians) } \\
\hline & & $\begin{array}{l}\text { Rating } \\
\text { period } 1\end{array}$ & $\begin{array}{l}\text { Rating } \\
\text { period } 2\end{array}$ & $\begin{array}{l}\text { Rating } \\
\text { period } 3\end{array}$ & $\begin{array}{l}\text { Rating } \\
\text { period } 1\end{array}$ & $\begin{array}{l}\text { Rating } \\
\text { period } 2\end{array}$ & $\begin{array}{l}\text { Rating } \\
\text { period } 3\end{array}$ \\
\hline \multirow[t]{8}{*}{$\mathrm{UnC}$} & A & 1 & 7 & 9 & 1 & 9 & 9 \\
\hline & B & 2 & 6 & 5 & 1 & 0 & 1 \\
\hline & $\mathrm{C}$ & 1 & 7 & 5 & 1 & 0 & 5 \\
\hline & $\mathrm{D}$ & 0 & 6 & 5 & 0 & 0 & 5 \\
\hline & $\mathrm{E}$ & 1 & 6.5 & 0 & 0 & 0 & 0 \\
\hline & $\mathrm{F}$ & 1 & 6 & 5 & 0 & 0 & 9 \\
\hline & G & 1 & 0 & 0 & 1 & 0 & 0 \\
\hline & $\mathrm{H}$ & 1 & 0 & 0 & 1 & 0 & 0 \\
\hline \multirow[t]{8}{*}{ UsC } & A & 1 & 6.5 & 9 & 1 & 9 & 9 \\
\hline & B & 2 & 8 & 1.5 & 4 & 0 & 5 \\
\hline & $\mathrm{C}$ & 1 & 8 & 5.5 & 0.5 & 0 & 5 \\
\hline & $\mathrm{D}$ & 1 & 6 & 5 & 2.5 & 0 & 5 \\
\hline & $\mathrm{E}$ & 0 & 6 & 0 & 1 & 0 & 0 \\
\hline & $\mathrm{F}$ & 1 & 8 & 8.5 & 2 & 0 & 8 \\
\hline & $\mathrm{G}$ & 0 & 0 & 0 & 1 & 0 & 0 \\
\hline & $\mathrm{H}$ & 1.5 & 0 & 0 & 2 & 0 & 0 \\
\hline
\end{tabular}

a direct comparison of the $\mathrm{mBB}($ median $=0$ ) and $\mathrm{mUN}$ $($ median $=0)$ variables. The results of a Wilcoxon test were not significant, $z=-0.58, p>.5$.

A Mann-Whitney $U$-test was conducted to determine whether our within-compound manipulation (UnC vs. UsC) affected the participants' memory for compounds in the expected manner. We used the number of correctly remembered compounds as the dependent variable in this test. The result of the test was statistically significant and was in the expected direction, $z=-2.32, p<.05$; this result indicates that, on average, the members of the UsC group had better memories for compounds (average rank $=52.51)$ than the members of the UnC group (average rank $=41.88$ ).

We then evaluated the backward blocking and unovershadowing effects in the $\mathrm{UsC}$ and $\mathrm{UnC}$ conditions. The medians and semi-interquartile ranges of these effects in the two groups suggest that both backward blocking and unovershadowing were obtained only in the UsC condition (see Fig. 1). This impression was confirmed using two Friedman tests; one test was used to assess each condition. The effect of cue (B vs. C vs. F) was not significant in the UnC condition, $\chi^{2}(2, N=52)=3.06, p>.1$, but it was highly significant in the UsC condition, $\chi^{2}(2, N=40)=$ $15.24, p<.001$. Wilcoxon tests were used to conduct follow-up comparisons of the data from Group UsC, and the results of these tests showed that the median rating for cue $\mathrm{F}$ was higher than the median rating for cue $\mathrm{C}(p=$ .061 ), although the test result did not meet our significance criterion. However, the results of a parallel comparison between the median rating for cue $\mathrm{F}$ and the median rating for the alternative control cue, D, were statistically significant $(p<.05)$. In addition, the median rating for cue $\mathrm{F}$ was significantly higher than the median rating for cue $\mathrm{B}(p<.001)$, and the median rating for cue $\mathrm{C}$ was also higher than that for cue $\mathrm{B}$ $(p<.005)$.

Although the results of the Friedman test were not significant in the UnC condition, we also conducted pairwise comparisons of the data obtained in this condition, for theoretical reasons. None of the comparisons that were made using these tests were significant; all $p$ values were $>.09$. Thus, it appears that the strengths of the within-compound associations were a key factor in obtaining both backward blocking and unovershadowing effects.

To look for convergent evidence regarding the role of within-compound associations in cue-interaction effects, additional Mann-Whitney $U$-tests were conducted to determine whether our independent variable (UnC vs. UsC) had also affected the values of the $\mathrm{mBB}$ and $\mathrm{mUN}$ variables. None of these tests yielded significant results, although there was a trend in the $\mathrm{mBB}$ variable, with higher values of $\mathrm{mBB}$ in the $\mathrm{UsC}$ than in the $\mathrm{UnC}$ conditions $[\mathrm{mBB}$, $z=-1.63, p=.103$; the same analysis (UnC vs. UsC) with mUN variable, $z=-1.03, p>.3$ ]. A parametric approach to examining these effects offers a similar pattern of results, with the exception of the $\mathrm{mBB}$ effect, which reaches statistical significance, indicating that the $\mathrm{mBB}$ 

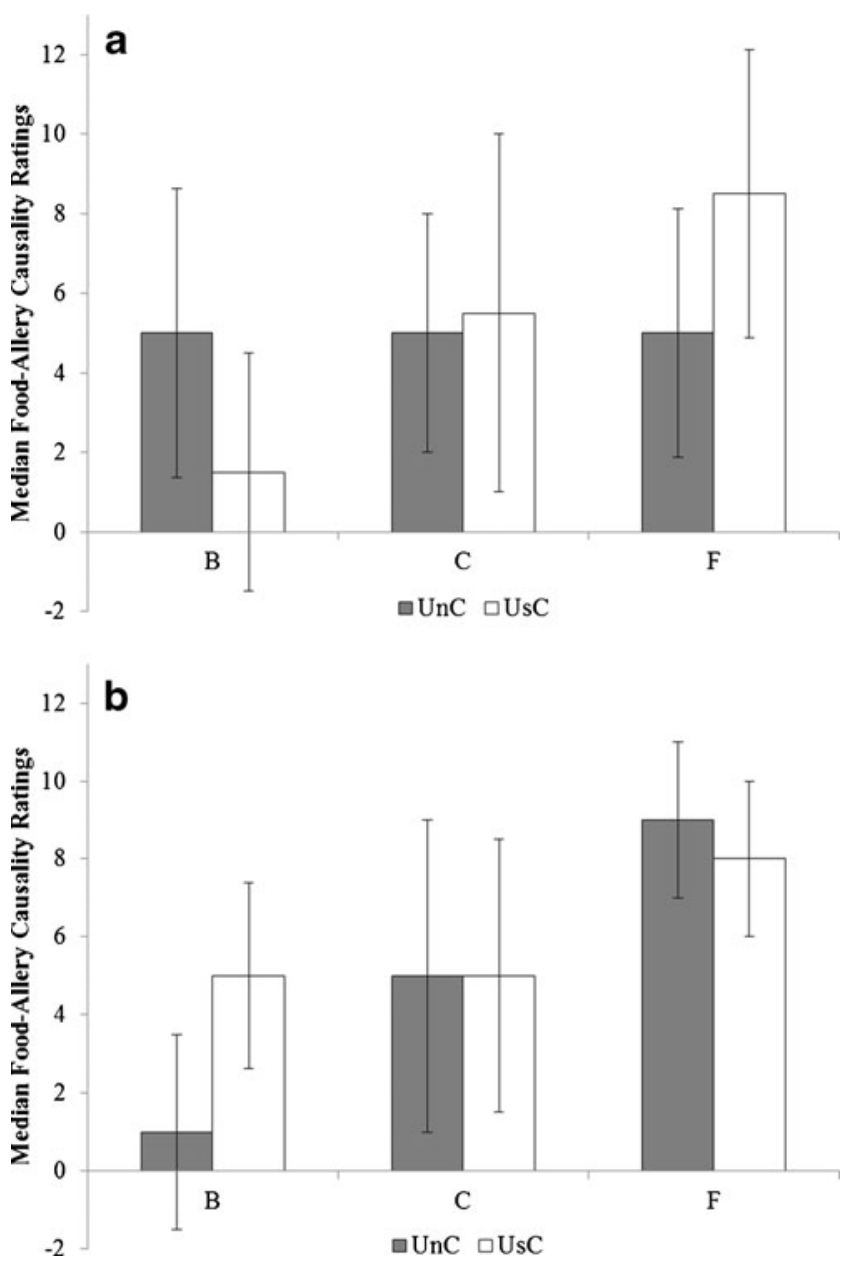

Fig. 1 Medians of food-allergy causality ratings at the end of phase 2 of each experiment (a Experiment 1; b Experiment 2). Error bars indicate semi-interquartile ranges. We represent overshadowing scores as the median of the values of the $\mathrm{C}$

measure differed between the $\mathrm{UnC}$ and $\mathrm{UsC}$ groups ${ }^{2}$ $[\mathrm{mBB}$, two-sample separate variance, $t(68.56)=-2.12$, $p<.05 ; \mathrm{mUN}, t(90)=-1.01, p>.3]$.

Thus, it appears that the comparison between $\mathrm{UnC}$ and UsC was not sufficiently sensitive to show a clear effect on the values of $\mathrm{mBB}$ and $\mathrm{mUN}$. There is, however, a more direct way to evaluate the role of within-compound associations in unovershadowing and backward blocking. Instead of dividing participants on the basis of an experimental manipulation, it is possible to sort them as a function of

\footnotetext{
${ }^{2}$ Parametric analyses were performed by applying the standard procedure that has typically been used in other articles about cue interaction in which causal judgments were treated as the dependent variable. For instance, descriptive statistics for the $\mathrm{mBB}$ and $\mathrm{mUN}$ variables were computed by calculating a single measure of overshadowing from the means of the ratings for cues $\mathrm{C}$ and $\mathrm{D}$. The magnitudes of the unovershadowing and backward blocking effects were then calculated by subtracting the new mean $\mathrm{CD}$ from the ratings for $\mathrm{F}(\mathrm{mUN})$ and then subtracting ratings for $\mathrm{B}$ from this mean $(\mathrm{mBB})$.
}

their memory test performance scores (i.e., their abilities to remember the compounds that were shown during training). Indeed, we expected that this grouping strategy might be more sensitive than a strategy of grouping on the basis of the types of stimuli that were used in the experimental task, because it is reasonable to expect that some participants in the UnC group were capable of learning the withincompound associations perfectly and that some participants in the UsC group were not capable of correctly learning the within-compound associations.

Therefore, we sorted participants into groups on the basis of their abilities to remember the within-compound associations, and we subsequently investigated whether there were any differences in the $\mathrm{mBB}$ and $\mathrm{mUN}$ values of these two groups (Table 3 ). We initially grouped participants according to the results of the standard memory test (Good-Rec vs. Poor-Rec) alone, but the results of the Mann-Whitney $U$ tests that we conducted for both variables were not significant (mBB, $z=-1.47, p>.1$; mUN, $z=-0.35, p>.5$ ). Importantly, we also assessed this hypothesis after using the second memory test to assign participants to the GoodRec\&Con and Poor-Rec\&Con groups. After grouping the participants in this manner, the results of both MannWhitney $U$-tests in the $\mathrm{mBB}$ and $\mathrm{mUN}$ variables met our significance criterion (mBB, $z=-3.03, p<.005$; mUN, $z=-2.06, p<.05$ ), which confirms that participants with stronger within-compound associations also demonstrated more substantial backward blocking and unovershadowing effects.

In summary, the statistical analysis of our data revealed reliable effects of both backward blocking and unovershadowing. These results are interesting in and of themselves because previous studies have failed to obtain both effects in a single experiment. For example, Larkin et al. (1998) obtained unovershadowing but not backward blocking, which led some authors to the conclusion that unovershadowing is a stronger effect than backward blocking and that it is easier to obtain (e.g., De Houwer, Beckers, \& Vandorpe, 2005). Indeed, simulations of a model proposed by Dickinson and Burke (1996) have shown that their model predicts that the unovershadowing effect in a given situation will be stronger than the backward blocking effect (Aitken \& Dickinson, 2005). In contrast to this prediction, both backward blocking and unovershadowing effects were obtained in the present experiment.

The most significant result was that both the backward blocking and unovershadowing effects were mediated by the strengths of the within-compound associations. Therefore, we can say that the results from Experiment 1 were consistent with the predictions of current associative learning theories, such as the associative learning models that have been proposed by Van Hamme and Wasserman (1994) and by Miller and Matzel (1988), in which the role of 
Table 3 Percentages of each category for the $\mathrm{mBB}$ and $\mathrm{mUN}$ variables in Experiment 1

\begin{tabular}{|c|c|c|c|c|c|c|c|c|c|c|}
\hline \multirow[t]{2}{*}{ Groups } & \multicolumn{5}{|c|}{$\operatorname{mBB}(\%)$} & \multicolumn{5}{|c|}{ mUN (\%) } \\
\hline & -2 & -1 & 0 & 1 & 2 & -2 & -1 & 0 & 1 & 2 \\
\hline $\mathrm{UnC}$ & 9.6 & 15.4 & 51.9 & 7.7 & 15.4 & 5.8 & 13.5 & 51.9 & 9.6 & 19.2 \\
\hline UsC & 5 & 7.5 & 52.5 & 12.5 & 22.5 & 10 & 0 & 50 & 22.5 & 17.5 \\
\hline Poor-Rec & 14.3 & 10.7 & 57.1 & 3.6 & 14.3 & 3.6 & 3.6 & 64.3 & 7.1 & 21.4 \\
\hline Good-Rec & 4.7 & 12.5 & 50 & 12.5 & 20.3 & 9.4 & 9.4 & 45.3 & 18.8 & 17.2 \\
\hline Poor-Rec\&Con & 9.3 & 14.8 & 61.1 & 5.6 & 9.3 & 7.4 & 9.3 & 61.1 & 7.4 & 14.8 \\
\hline Good-Rec\&Con & 5.3 & 7.9 & 39.5 & 15.8 & 31.6 & 7.9 & 5.3 & 36.8 & 26.3 & 23.7 \\
\hline
\end{tabular}

within-compound associations is crucial in the mediation of both backward blocking and unovershadowing effects.

\section{Experiment 2}

For theoretical reasons, debate regarding the roles that within-compound associations play in cue-interaction effects has focused on retrospective revaluation phenomena. The reason for this focus is that most accounts of retrospective revaluation phenomena propose that within-compound associations affect cue-interaction effects only in their backward versions (Dickinson \& Burke, 1996; Van Hamme \& Wasserman, 1994).

Nevertheless, some experiments have also included forward cue-interaction conditions that are similar to retrospective revaluation conditions but that reverse the order of the learning phases (see Table 1). Experiments that have assessed the role of within-compound associations in forward cue-interaction phenomena have been aimed at investigating whether, as the comparator hypothesis predicts, within-compound associations play the same roles in forward cue interaction and in retrospective revaluation (Stout \& Miller, 2007). The results of several causal learning experiments that have been conducted using human participants appear to refute this prediction (Aitken et al., 2001; Dickinson \& Burke, 1996; Melchers et al., 2004, 2006), but a study by Amundson, Witnauer, Pineño, and Miller (2008) showed that within-compound associations could mediate overshadowing in three different conditioning experiments that utilized rats. Although there are some cases in which an overshadowing condition can be used as a control condition for other types of cue-interaction effects, such as Experiment 1 of this study, overshadowing itself can be considered a cueinteraction phenomenon, because cues that are presented together compete with each other. On the basis of their own results, Amundson et al. concluded that withincompound associations not only are necessary for retrospective revaluation, but also are necessary for forward cue-interaction effects.
An important limitation of previous work regarding the role of within-compound associations in cue-interaction phenomena is that none of the human causal learning experiments that have assessed the role of withincompound associations in forward cue-interaction phenomena have included an appropriate control for overshadowing. This makes it impossible to draw any conclusions about the specific role(s) of within-compound associations in forward blocking and/or reduced overshadowing. Although Vandorpe and De Houwer (2005) studied both effects in human causal learning and used the correct control condition, these authors did not assess the roles that withincompound associations played in mediating the two cueinteraction effects. They did find that the reduced overshadowing effect was generally larger than the forward blocking effect in their study, which they have interpreted as being inconsistent with associative learning models and consistent only with an inferential account of cue interaction in causal learning.

The main goal of the following experiment was to determine whether within-compound associations have an impact on forward blocking and reduced overshadowing. Moreover, it seems relevant to test the generality of the result that was obtained by Vandorpe and De Houwer (2005) by trying to replicate it, particularly because they concluded that their result was inconsistent with the predictions of associative learning models. Thus, replicating their result was a secondary goal of the present experiment.

Method

Participants, apparatus, stimuli, and procedure

In total, 59 students at the University of Malaga School of Psychology received course credit for their voluntary participation in our study. The students were randomly assigned to the two main experimental condition groups; specifically, 31 students were included in the UnC condition group, and 28 students were included in the UsC condition group. All of the experimental apparatuses, stimuli, and procedures 
were the same as those used in Experiment 1, with the exception that the order in which learning phases 1 and 2 took place was reversed (see Table 1).

Results and discussion

We followed the same strategy for analyzing the data that we used in Experiment 1. We conducted a Friedman test of ratings from the third questionnaire in which we contrasted the median ratings of cues $\mathrm{B}($ median $=4), \mathrm{C}($ median $=5)$, and $\mathrm{F}$ (median $=9$ ) to determine whether we had obtained effects of forward blocking and reduced overshadowing. The results of this analysis were significant, $\chi^{2}(2, N=59)=$ 24.06, $p<.001$. Pairwise comparisons that were conducted using Wilcoxon tests showed that the median rating for cue $\mathrm{F}$ was higher than those for both cues B $(p<.001)$ and $\mathrm{C}$ $(p<.001)$. In addition, the median rating that was associated with cue $\mathrm{C}$ was higher than that for cue $\mathrm{B}$ $(p<.05)$. Thus, we obtained reliable forward blocking and reduced overshadowing effects. As a means of evaluating the generality of the results that were obtained by Vandorpe and De Houwer (2005), we also compared the strengths of the two forward cue-interaction effects by directly comparing the variable that we used as a measure of the magnitude of forward blocking, $\mathrm{mFB}$ (median =1), with the variable that we used as a measure of the magnitude of reduced overshadowing, $\mathrm{mRO}$ (median $=1)$. A nonsignificant result was obtained from a Wilcoxon test (mFB vs. mRO: $\mathrm{z}=-0.24, \mathrm{p}>.8$ ). Our result was still far from reaching statistical significance, $t(58)=-0.82, p>.4$, when using dependent variables and a parametric approach to analyzing the data that were identical to those used by Vandorpe and De Houwer (2005).

A Mann-Whitney $U$-test was conducted to determine whether the UnC versus $\mathrm{UsC}$ experimental manipulation affected the participants' memory for compound stimuli as expected. As in Experiment 1, we used the number of correctly remembered compounds as the dependent variable. The result of this test was statistically significant and was in the expected direction, $z=-3.85, p<.001$, which indicated that, on average, participants in the UsC group were better at remembering the identities of the trained compounds (average rank $=37.07$ ) than were participants in the UnC group (average rank $=23.61$ ).

We then evaluated forward blocking and reduced overshadowing effects in both the UsC and UnC groups. The medians and semi-interquartile ranges of these effects in the two groups suggest that there was a reliable cue-interaction effect in both UsC and UnC groups (see Fig. 1). The effect of cue (B vs. C vs. F) was significant in the UnC group, $\chi^{2}(2, N=31)=16.90$, $p<.001$. Follow-up comparisons were conducted using Wilcoxon tests and showed that the median rating for cue $\mathrm{F}$ was higher than those for both cue C $(p<.005)$ and cue B $(p<.001)$. In addition, the median rating for cue $\mathrm{C}$ was higher than that for cue $\mathrm{B}(p<.05)$. The effect of cue (B vs. C vs. F) was also significant for participants in the UsC group, $\chi^{2}(2, N=$ $28)=7.70, p<.05$. Follow-up comparisons showed that the median rating for cue $\mathrm{F}$ was higher than those for cues $\mathrm{C}$ $(p<.05)$ and $\mathrm{D}$ (although the comparison between the median ratings for cue $\mathrm{F}$ and the control cue $\mathrm{D}$ was only marginally significant, $p=.054)$. The median rating for cue $\mathrm{F}$ was also higher than that for cue $\mathrm{B}(p<.005)$. In contrast, the median rating for cue $\mathrm{C}$ did not differ from the median rating for cue $\mathrm{B}$ $(p>.3)$. Thus, a simple forward blocking effect was not observed among members of the UsC group.

In accordance with the logic behind the analyses that were conducted in Experiment 1, additional Mann-Whitney $U$-tests were conducted to investigate whether the manipulation of the stimuli (UnC vs. UsC) had also affected the values of the $\mathrm{mFB}$ and $\mathrm{mRO}$ variables. However, none of these tests yielded significant results (mFB, $z=-1.56, p=.119$; mRO, $z=-1.03, p>.8$ ), indicating no difference in the magnitude of forward blocking and reduced overshadowing between both groups (UnC vs. UsC).

To further assess the role(s) played by within-compound associations in forward blocking and reduced overshadowing, we sorted participants into different groups according to their memories for the within-compound associations, as in Experiment 1. We then tested for between-group (UnC vs. UsC) differences in the values of the $\mathrm{mFB}$ and $\mathrm{mRO}$ variables (Table 4). We first grouped the participants on the basis of their standard recognition test scores alone (which

Table 4 Percentages of each category for the $\mathrm{mFB}$ and $\mathrm{mRO}$ variables in Experiment 2

\begin{tabular}{|c|c|c|c|c|c|c|c|c|c|c|}
\hline \multirow[t]{2}{*}{ Groups } & \multicolumn{5}{|c|}{$\mathrm{mFB}(\%)$} & \multicolumn{5}{|c|}{$\operatorname{mRO}(\%)$} \\
\hline & -2 & -1 & 0 & 1 & 2 & -2 & -1 & 0 & 1 & 2 \\
\hline $\mathrm{UnC}$ & 3.2 & 9.7 & 29 & 29 & 29 & 3.2 & 9.7 & 35.5 & 29 & 22.6 \\
\hline UsC & 3.6 & 17.9 & 35.7 & 32.1 & 10.7 & 10.7 & 3.6 & 32.1 & 35.7 & 17.9 \\
\hline Poor-Rec & 6.3 & 6.3 & 37.5 & 37.5 & 12.5 & 0 & 6.3 & 43.8 & 43.8 & 6.3 \\
\hline Good-Rec & 2.3 & 16.3 & 30.2 & 27.9 & 23.3 & 9.3 & 7 & 30.2 & 27.9 & 25.6 \\
\hline Poor-Rec\&Con & 3.8 & 7.7 & 34.6 & 34.6 & 19.2 & 3.8 & 3.8 & 34.6 & 42.3 & 15.4 \\
\hline Good-Rec\&Con & 3 & 18.2 & 30.3 & 27.3 & 21.2 & 9.1 & 9.1 & 33.3 & 24.2 & 24.2 \\
\hline
\end{tabular}


resulted in the generation of the Good-Rec and Poor-Rec groups). Subsequent Mann-Whitney $U$-tests showed no significant difference between Good-Rec and Poor-Rec groups for either $\mathrm{mFB}$ or $\mathrm{mRO}(\mathrm{mFB}, z=-0.25, p>.8$; $\mathrm{mRO}, z=-0.44, p>.6$ ). We also assessed this hypothesis using the results of the second memory test to assign participants to the Good-Rec\&Con and Poor-Rec\&Con groups. Again, the results of both Mann-Whitney $U$ tests were far from reaching statistical significance (mFB, $z=-0.45, p>.6$; mRO, $z=-0.55, p>.6$ ).

In summary, the results of Experiment 2 demonstrated the presence of a reliable forward cue-interaction effect. We also obtained evidence of both forward blocking and reduced overshadowing. Importantly, our results supported the idea that within-compound associations are not involved in any forward cue-interaction phenomena; thus, our results are consistent with the Van Hamme-Wasserman and DickinsonBurke models of associative learning. Moreover, the absence of evidence supporting the notion that within-compound associations mediate forward blocking and reduced overshadowing effects cannot be explained by the comparator hypothesis (Stout \& Miller, 2007).

We also assessed the generality of the asymmetrical cueinteraction effects that were obtained by Vandorpe and De Houwer (2005). We were not able to replicate their results in the present experiment, even when we used identical dependent variables and exactly the same method of analysis.

Surprisingly, we failed to find a significant forward blocking effect among members of the UsC group. It is important to note, however, that the strength of the forward blocking effect did not differ between the UnC and UsC groups and that when the entire sample was considered, the forward blocking effect was significant using both control conditions, $\mathrm{C}$ and $\mathrm{D}$. Thus, the nonsignificant forward blocking effect in the UsC group can be attributed to a loss of statistical power. In any case, the main findings of Experiment 2 were that (1) we found significant forward blocking and reduced overshadowing effects and (2) these effects did not appear to be impacted by various aspects of within-compound associations.

In addition, we conducted some cross-experimental analyses. The results of these analyses should be interpreted with caution because between-experiment comparisons are never as convincing as within-experiment comparisons. However, given the similarity between the procedures that were used in the two experiments, we explored some theoretically interesting comparisons. Specifically, comparing the results of Experiments 1 and 2 could allow us to examine the effect that the order of the training phases used in each paradigm (backward vs. forward, respectively) has on the magnitudes of the cue-interaction effects in groups UnC and UsC. On the one hand, we did not expect to find any differences in cue-interaction effects in the UsC group, regardless of the order of the phases. On the other hand, however, we expected to find that the forward condition would be associated with larger cue-interaction effects in the UnC group when compared with the cueinteraction effects that were associated with the backward condition.

The dependent variables that we used in these analyses were the magnitudes of the cue-interaction effects. We had two dependent variables - namely, the magnitude of backward blocking or forward blocking (BB/FB) and the magnitude of unovershadowing or reduced overshadowing (UN/ RO). We conducted two separate Mann-Whitney $U$-tests for each within-compound condition ( $\mathrm{UnC}$ and $\mathrm{UsC}$ ) and for each of the two dependent variables (BB/FB and UN/RO). The independent variable in each of the analyses was the order of the phases (forward vs. backward). The analysis of the effect on participants in the UnC group showed that the order of the phases significantly affected the BB/FB cueinteraction effect, $\mathrm{z}=-2.69, p<.01$ (forward average rank = 50.77 ; backward average rank $=36.77$ ), and that there was a similar trend for the UN/RO effect, $\mathrm{z}=-1.589, p=.11$ (forward average rank $=47.10$; backward average rank $=$ 38.96). In contrast to this finding, no significant effects were observed in the analyses of the data from participants in the UsC group ( $p$ values $>.5$ ). It appears that the cue-interaction effects in the UsC group were generally large regardless of the order in which the phases were presented, so there were no significant effects of the order of the learning phases on the cue-interaction effects that were measured among participants in this condition.

\section{General discussion}

In light of the results of the present study and the results of previous studies, it appears to be quite clear that withincompound associations play an important role in mediating retrospective revaluation effects (e.g., Dickinson \& Burke, 1996). To date, however, and despite evidence in support of the role of within-compound associations in retrospective revaluation effects, it has not been determined whether these associations have identical impacts on backward blocking and unovershadowing. In the present study, we have shown that within-compound associations play roles in the modulation of both backward blocking and unovershadowing (Experiment 1). However, we failed to establish the presence of a within-compound association effect on forward cue-interaction phenomena, such as forward blocking and reduced overshadowing (Experiment 2). The general pattern of results that were obtained in the present study is consistent with the predictions made by modern learning theories (e.g., Van Hamme \& Wasserman, 1994). 
Despite the numerous experiments that have already assessed the role of within-compound associations in cue interaction, it is remarkable that nearly all of the previous studies in which the strengths of the within-compound associations were manipulated failed to include control conditions that were appropriate for the independent assessment of backward blocking and unovershadowing (e.g., Dickinson \& Burke, 1996). A notable exception is a study conducted by Larkin et al. (1998). In the first experiment of their study, they manipulated within-compound associations using an experimental design that included both backward blocking and unovershadowing conditions; their design was very similar to the design that we used for Experiment 1.

Larkin et al. (1998) manipulated the strength of the within-compound associations in their study by varying the number of compound trials (three vs. six). Although this manipulation affected the participants' abilities to remember the identities of various compound stimuli, it had no effect on either backward blocking or unovershadowing. Indeed, in both Experiments 1 and 2 of their study, they only obtained unovershadowing, not backward blocking. In Experiment 3 of their study, they manipulated the withincompound associations in accordance with a strategy that was proposed by Dickinson and Burke (1996); namely, they included a varied condition in which they paired the target cues with several filler cues in an attempt to weaken the within-compound associations. Using that paradigm, Larkin et al. (1998) found that the unovershadowing effect was weaker among participants in the varied condition group than among participants in the consistent condition group.

Larkin et al. (1998) interpreted these results as being contrary to the model proposed by Van Hamme and Wasserman (1994). Van Hamme and Wasserman adapted the well-known Rescorla-Wagner model to include the complementary assumption that the associative strengths of cues that are absent but expected can also change. However, the associative change that occurs due to an absent cue is the opposite of the change that occurs due to a cue that is present; associations are weakened if the outcome that is associated with an absent cue is presented, and they are strengthened if the outcome is also absent. For instance, in a backward blocking design, the model proposed by Van Hamme and Wasserman predicts that the associative link $\mathrm{B} \rightarrow \mathrm{O}$ will become weaker during the second learning phase because the cue $\mathrm{B}$ is absent, but expected (by virtue of its within-compound association with cue A), and the outcome associated with it is present. Thus, the model proposed by Van Hamme and Wasserman predicts both backward blocking and unovershadowing effects, and it suggests that both effects are mediated by withincompound associations (or other factors that cause an absent cue to be expected during the second learning phase of a causal learning experiment). Thus, it is difficult to reconcile the results that were obtained by Larkin et al. (1998) with the predictions of Van Hamme and Wasserman's model.

Larkin et al. (1998) argued that their results could be better accounted for by Dickinson and Burke's (1996) adaptation of Wagner's (1981) SOP model. The original SOP model proposed that the representation of each stimulus is composed of simpler elements. Each one of these elements can be in one of three different activation states: an inactive (I) state, a high activity (A1) state, or a low activity (A2) state. According to Wagner's model, the elements of which a stimulus is composed pass from state I to state A1 when the stimulus is presented. This activation decreases over time, and the stimulus elements pass progressively from state A1 to state A2 and then from state A2 to state I. In addition, elements that have been activated by an associative link (instead of being activated by the direct presentation of the stimulus) pass directly from state I to state A2. According to the original SOP model, learning occurs only when elements of a cue are in state $\mathrm{A} 1$; if the elements that make up the outcome are in state A1 at the same time that the elements of the cue are in state A1, the excitatory link between the cue and the outcome is strengthened. In contrast, if elements of the outcome are in state A2, an inhibitory link between the cue and a given outcome element develops.

Two more assumptions were added to the revised SOP model proposed by Dickinson and Burke (1996). First, if both cue and outcome elements are in state A2 at the same time, the excitatory link between these elements is strengthened. Second, if the cue elements are in state A2 and the associated outcome elements are in state A1, the inhibitory link between these elements is strengthened.

It is easy to explain the unovershadowing effect that was observed by Larkin et al. (1998) within this framework. During the second learning phase of the design of their unovershadowing experiment, some elements of cue $\mathrm{F}$ are in activation state $\mathrm{A} 2$ at the time that cue $\mathrm{E}$ is presented because of a within-compound association that has formed between cues $\mathrm{E}$ and $\mathrm{F}$. In these trials, the presentation of cue $E$ also results in the activation of some of the outcome elements to state $\mathrm{A} 2$ as a result of the $\mathrm{E} \rightarrow \mathrm{O}$ association that was learned during the first learning phase. Thus, elements of both $\mathrm{F}$ and $\mathrm{O}$ are simultaneously in state $\mathrm{A} 2$ during these trials, and the excitatory association between cue $\mathrm{F}$ and outcome $\mathrm{O}$ is therefore strengthened.

Interestingly, Larkin et al. (1998; see also Aitken \& Dickinson, 2005) showed that the predictions of the modified SOP model are more complicated in the case of backward blocking. During the second learning phase of a backward blocking experiment, the presentation of cue A results in the activation of elements of cue B to state A2. The outcome elements in these trials are also in state $\mathrm{A} 2$ because of activation that has spread from cue A. However, because the 
outcome is actually present, some of its elements will also be in state A1. Thus, the outcome has some elements in state A1 and some elements in state $\mathrm{A} 2$, which then allows for the simultaneous development of both excitatory and inhibitory associations between the absent cue, B, and the outcome. The mixture of oppositely signed associations between cue B and the outcome would then cause the absence of backward blocking (for further details, see Aitken \& Dickinson, 2005). Note that this analysis predicts the absence of backward blocking, regardless of the strength of the within-compound associations, because within-compound associations in this context would promote the formation of both excitatory and inhibitory associations between cue B and the outcome.

Our results do not concur with the results that were obtained by Larkin et al. (1998), nor do they support the predictions of the revised SOP model. We obtained reliable effects of both backward blocking and unovershadowing. Furthermore, both of these effects depended strongly on the strength of the within-compound associations. Thus, it appears that the model that was advanced by Van Hamme and Wasserman (1994) offers a better account of the results of the present study than does the modified SOP model proposed by Dickinson and Burke (1996).

In accordance with a very different line of reasoning, some researchers have attempted to explain cue-interaction phenomena in terms of inferential processes. From their point of view, associative learning processes do not play any role in human causal learning. Instead, they argue that learning occurs as a result of inferential and propositionbased reasoning (De Houwer, 2009). For instance, participants in an unovershadowing experiment would create the proposition that "when patient $\mathrm{X}$ eats foods $\mathrm{E}$ and $\mathrm{F}$, he or she develops an allergic reaction" during the first learning phase. During the second phase, these participants would subsequently add another premise to their propositionnamely, "when patient $\mathrm{X}$ eats food $\mathrm{E}$ alone (without F), he or she does not develop an allergic reaction." On the basis of these two premises, the participants would then conclude that food E does not contribute to the patient's allergy and that $\mathrm{F}$ must, therefore, be the genuine cause of the allergy.

The inferential account also predicts that withincompound associations should affect retrospective revaluation phenomena and should not affect forward cue interaction phenomena (Mitchell, Killedar, \& Lovibond, 2005). To continue with the example of unovershadowing, concluding that cue $\mathrm{F}$ is the genuine cause of the allergic reaction requires that during the second learning phase, the participant must remember that the cue that accompanied cue $\mathrm{E}$ during the first phase was cue F. This memory is not relevant in the case of forward cue-interaction effects, because the inference could be made from trials in the second learning phase in which both cues are presented together. Thus, an inferential view could reasonably account for the main findings of our experiments.

It is reasonable to wonder why some of the results of the present experiments differ from the results of very similar previous experiments. In Experiment 1, we found similar magnitudes for both the backward blocking and unovershadowing effects; this finding is contrary to the results of other experiments, such as the results of Experiments 1 and 2 in the aforementioned study by Larkin et al. (1998). A reasonable explanation for this is that the participants in Experiment 1 of our study remembered the withincompound associations particularly well. Indeed, our manipulation of the within-compound associations attempted to improve participants' abilities to remember the associations, so it is therefore not surprising that the vast majority of the participants remembered at least three of the four compounds. Thus, if we admit that withincompound associations are crucial for obtaining a backward blocking effect, backward blocking effects would be obtained only in experiments in which the participants were good at remembering the identities of the compounds.

Because a reliable effect of unovershadowing was obtained in all three of the experiments conducted by Larkin et al. (1998), one way of accounting for their results could be that the magnitudes of backward blocking and unovershadowing effects differ in terms of their relation to a within-compound association variable. More research is needed to further elucidate the details of the relationship between within-compound associations and the aforementioned cue-interaction effects.

As was mentioned above, Vandorpe and De Houwer (2005) obtained reduced overshadowing effects that were stronger than the forward blocking effects that they observed. We were not able to replicate their result, even when using the same method of data analysis, rather than the nonparametric analysis method that has been used extensively in this report. Similarly, Chapman (1991, Experiment 1) also found both effects in the same experiment. In light of the evidence presented in both Chapman's study and ours, and considering that the experiment conducted by Vandorpe and De Houwer included only 18 participants, it seems reasonable to question their conclusion that a reduced overshadowing effect can be obtained more easily than a forward blocking effect.

Finally, we think that some methodological issues in this study warrant a brief comment. First, the results of Experiment 1 showed that using a combination of the results of the recognition and confidence tests predicted retrospective revaluation effects more accurately than did using data from the recognition test alone. Thus, we encourage researchers to use this type of Likert-like item when measuring the strength of within-compound associations (see also Larkin et al., 1998). 
Second, we have shown that cue-interaction phenomena can also be studied by treating Likert-type items as ordinal variables. Treating the Likert-type items as ordinal variables in this experiment neither limited the number of hypotheses that we were able to test nor prevented us from performing all of the usual analyses, including analyses in which the magnitudes of the effects were used as dependent variables. In addition, we controlled for type I and II errors without making any assumptions about the particular distribution(s) of our dependent variables. Importantly, our analysis methods also allowed us to minimize the extent to which we made assumptions about the underlying metric used by the participants to score the perceptions of causal strength that they reported in the questionnaires (for a similar argument, see Chapman, 1991).

Author's Note This research was supported by Grant P11-SEJ-7898 from the Junta de Andalucía to David Luque and Grant PI2012-56 from the Basque Government to Miguel A. Vadillo. Amanda Flores was supported by an FPI scholarship that was awarded by Junta de Andalucía. We thank Joaquín Morís for his help with statistical analyses. Correspondence concerning this article should be addressed to the Departamento de Psicología Básica, Facultad de Psicología, Universidad de Málaga, Campus de Teatinos, s/n, 29072, Málaga, Spain e-mail: david.luque@gmail.com

\section{References}

Aitken, M. R. F., \& Dickinson, A. (2005). Simulations of a modified SOP model applied to retrospective revaluation of human causal learning. Learning \& Behavior, 33, 147-159. doi:10.3758/BF03196059

Aitken, M. R. F., Larkin, M. J. W., \& Dickinson, A. (2001). Reexamination of the role of within-compound associations in the retrospective revaluation of causal judgments. Quarterly Journal of Experimental Psychology, 54B, 27-51.

Amundson, J. C., Witnauer, J. E., Pineño, O., \& Miller, R. R. (2008). An inhibitory within-compound association attenuates overshadowing. Journal of Experimental Psychology. Animal Behavior Processes, 34, 133-143. doi:10.1037/0097-7403.34.1.133

Chapman, G. B. (1991). Trial order affects cue interaction in contingency judgment. Journal of Experimental Psychology: Learning, Memory, and Cognition, 17, 837-854.

De Houwer, J. (2009). The propositional approach to associative learning as an alternative for association formation models. Learning \& Behavior, 37, 1-20. doi:10.3758/LB.37.1.1

De Houwer, J., Beckers, T., \& Vandorpe, S. (2005). Evidence for the role of higher order reasoning processes in cue competition and other learning phenomena. Learning \& Behavior, 33, 239-249. doi:10.3758/BF03196066

Dickinson, A., \& Burke, J. (1996). Within-compound associations mediate the retrospective revaluation of causality judgements. Quarterly Journal of Experimental Psychology, 49B, 60-80.

Dickinson, A., Shanks, D. R., \& Evenden, J. L. (1984). Judgement of act-outcome contingency: The role of selective attribution. Quarterly Journal of Experimental Psychology, $36 A, 29-50$

Ghirlanda, S. (2005). Retrospective revaluation as simple associative learning. Journal of Experimental Psychology. Animal Behavior Processes, 31, 107-111. doi:10.1037/0097-7403.31.1.107
Gopnik, A., Glymour, C., Sobel, D. M., Schulz, L. E., Kushnir, T., \& Danks, D. (2004). A theory of causal learning in children: Causal maps and Bayes nets. Psychological Review, 111, 3-32. doi:10.1037/ 0033-295X.111.1.3

Holyoak, K. H., \& Cheng, P. W. (2011). Causal learning and inference as a relational process: The new synthesis. Annual Review of Psychology, 62, 135-163. doi:10.1146/annurev.psych.121208.131634

Kahler, E., Rogausch, A., Brunner, E., \& Himmel, W. (2008). A parametric analysis of ordinal quality-of-life data can lead to erroneous results. Journal of Clinical Epidemiology, 61, 475-480.

Kamin, L. J. (1968). "Attention-like" processes in classical conditioning. In M. R. Jones (Ed.), Miami Symposium on the Prediction of Behavior, 1967: Aversive Stimulation (pp. 9-31). Coral Gables, FL: University of Miami.

Kruschke, J. K., \& Blair, N. J. (2000). Blocking and backward blocking involve learned inattention. Psychonomic Bulletin \& Review, 7, 636-645. doi:10.3758/BF03213001

Larkin, M. J., Aitken, M. R. F., \& Dickinson, A. (1998). Retrospective revaluation of causal judgments under positive and negative contingencies. Journal of Experimental Psychology: Learning, Memory, and Cognition, 24, 1331-1352.

López, F. J., \& Shanks, D. R. (2008). Models of animal learning and their relations to human learning. In R. Sun (Ed.), Handbook of computational cognitive modelling (pp. 589-611). Cambridge, MA: Cambridge University Press.

Markman, A. B. (1989). LMS rules and the inverse base-rate effect: Comment on Gluck and Bower (1988). Journal of Experimental Psychology. General, 118, 417-421. doi:10.1037//0096-3445.118.4.417

Melchers, K. G., Lachnit, H., \& Shanks, D. R. (2004). Within-compound associations in retrospective revaluation and in causal learning: A challenge for comparator theory. Quarterly Journal of Experimental Psychology, 57B, 25-53. doi:10.1080/02724990344000042

Melchers, K. G., Lachnit, H., \& Shanks, D. R. (2006). The comparator theory fails to account for the selective role of within-compound associations in cue-selection effects. Experimental Psychology, 53, 316-320. doi:10.1027/1618-3169.53.4.316

Miller, R. R., \& Matzel, L. D. (1988). The comparator hypothesis: A response rule for the expression of associations. In G. H. Bower (Ed.), The psychology of learning and motivation (Vol. 22, pp. 51-92). San Diego, CA: Academic Press.

Mitchell, C. J., De Houwer, J., \& Lovibond, P. F. (2009). The propositional nature of human associative learning. The Behavioral and Brain Sciences, 32, 183-198. doi:10.1017/S0140525X09000855

Mitchell, C. J., Killedar, A., \& Lovibond, P. F. (2005). Inference-based retrospective revaluation in human causal judgments requires knowledge of within-compound relationships. Journal of Experimental Psychology. Animal Behavior Processes, 31, 418424. doi:10.1037/0097-7403.31.4.418

Mitchell, C. J., Lovibond, P. F., \& Gan, C. Y. (2005). A dissociation between causal judgment and outcome recall. Psychonomic Bulletin \& Review, 12, 950-954. doi:10.3758/BF03196791

Munzel, U., \& Bandelow, B. (1998). The use of parametric vs. non parametric tests in the statistical evaluation of rating scales. Pharmacopsychiatry, 31, 222-224.

Norris, C. M., Ghali, W. A., Saunders, L. D., Brant, R., \& Galbraith, P. D. (2004). Systematic review of statistical methods used to analyze Seattle Angina Questionnaire scores. The Canadian Journal of Cardiology, 20, 187-193.

Rescorla, R. A., \& Wagner, A. R. (1972). A theory of Pavlovian conditioning: Variations in the effectiveness of reinforcement and nonreinforcement. In A. H. Black \& W. F. Prokasy (Eds.), Classical conditioning II: Current research and theory (pp. 6499). New York: Appleton-Century-Crofts.

Shah, D. A., \& Madden, L. V. (2004). Nonparametric analysis of ordinal data in designed factorial experiments. Phytopathology, 94, 33-34. 
Shanks, D. R. (1985). Forward and backward blocking in human contingency judgment. Quarterly Journal of Experimental Psychology, 37B, 1-21.

Shanks, D. R. (2007). Associationism and cognition: Human contingency learning at 25. Quarterly Journal of Experimental Psychology, 60, 291-309. doi:10.1080/17470210601000581

Shanks, D. R. (2010). Learning: From association to cognition. Annual Review of Psychology, 61, 271-301. doi:10.1146/ annurev.psych.093008.100519

Siegel, S., \& Castellan, N. J. (1988). Nonparametric statistics for the behavioral sciences (2nd Ed.). New York: McGraw-Hill.

Singer, J. M., Poleto, F. Z., \& Rosa, P. (2004). Parametric and nonparametric analyses of repeated ordinal categorical data. Biometrical Journal, 46, 460-473.

Stout, S. C., \& Miller, R. R. (2007). Sometimes competing retrieval (SOCR): A formalization of the comparator hypothesis. Psychological Review, 114, 759-783. doi:10.1037/0033-295X.114.3.759

Sutton, R. S., \& Barto, A. G. (1981). Toward a modern theory of adaptive networks: Expectation and prediction. Psychological Review, 88, 135-170.

Tassoni, C. J. (1995). The least mean squares network with information coding: A model of cue learning. Journal of Experimental Psychology: Learning, Memory, and Cognition, 21, 193-204. doi:10.1037//0278-7393.21.1.193
Vandorpe, S., \& De Houwer, J. (2005). A comparison of forward blocking and reduced overshadowing in human causal learning. Psychonomic Bulletin \& Review, 12, 945-949. doi:10.3758/ BF03196790

Vandorpe, S., De Houwer, J., \& Beckers, T. (2007). The role of memory for compounds in cue competition. Learning and Motivation, 38, 195-207. doi:10.1016/j.1mot.2007.03.001

Van Hamme, L. J., \& Wasserman, E. A. (1994). Cue competition in causality judgments: The role of nonpresentation of compound stimulus elements. Learning and Motivation, 25, 127-151.

Wagner, A. R. (1981). SOP: A model of automatic memory processing in animal behavior. In N. E. Spear \& R. R. Miller (Eds.), Information processing in animals: Memory mechanisms (pp. 547). Hillsdale, NJ: Erlbaum.

Wasserman, E. A. (1990). Attribution of causality to common and distinctive elements of compound stimuli. Psychological Science, 1, 298-302. doi:10.1111/j.1467-9280.1990.tb00221.x

Wasserman, E. A., \& Berglan, L. R. (1998). Backward blocking and recovery from overshadowing in human causal judgement: The role of within-compound associations. Quarterly Journal of Experimental Psychology, 51B, 121-138.

Wasserman, E. A., \& Castro, L. (2005). Surprise and change: Variations in the strength of present and absent cues in causal learning. Learning \& Behavior, 33, 131-146. doi:10.3758/BF03196058 